\title{
WATER EXPOSED TO MAGNETIC TREATMENT: MUSKMELON (CANTALOUPE) GROWING
}

\author{
M. HARARI \\ "Arava" Experimental Station, Yotvata, Israel \\ and
}

\section{J. LIN}

Department of Mineral Engineering, Technion-Israel Institute of Technology, Haifa, 32000 Israel

(Received May 9, 1991)

Abstract. This paper surveys recent experimental results of investigation of the influence of an exposure of irrigation water to magnetic field on yield, quality parameters and duration of fruit-bearing of cantaloupe.

\section{INTRODUCTION}

Under a broadly based master plan for the investigation of output and yield in both livestock and field-crop farming [1], and following a similar work in the former East-block countries [2,3], a test was carried out under field conditions on Yotvata farm of the "Arava" Research Station involving spring-melons of the Arava variety.

The principal objective was to examine the influence of an upstream short magnetic exposure on such important plant parameters such as yield, nutritional minerals content and length of fruit-bearing period.

\section{MATERIALS AND METHODS}

On the Yotvata farm of the Arava Research Station, muskmelons of the Arava variety were sown on December 27,1987 . The soil is sandy to clayey-sandy. The mean electrical conductance of the irrigation water was $3.37 \mathrm{mmho} / \mathrm{cm}$. The procedures for land preparation and plant protection during growth were standard procedures of southern Arava. Fertilization, irrigation and preventive treatment with respect to field crops followed the recommendations of the Ministry of Agriculture, the Extension Service. 
The irrigation equipment was a standard commercial "Netafim" 2 ith doip irrigation system. The fertilization was carried out all along the irrigation using TMB fertilizer pump.

On February 11, 1988, at the plant age of three true leaves, the magnetic treatment of the irrigation water was began using an improved magnetic apparatus (*). The experiment was designed as a random pattern with six replications. Each plot had an area of $81 \mathrm{~m}^{2}$. Suction cups were installed to measure the soil solution composition at an interval of every second irrigation.

"Treated" (irrigated with magnetically treated water) and control plots received equal amounts of water and fertilizer. Chemical composition and electrical conductivity of the irrigation water were measured at drippers, too, as a further control.

During the period of growth, four observations of the vegetative plant parameters were made, namely: length of the vine, number and size of leaves, number and location of female blossoms, the colour tone of the leaves of different age, the size, location and number of fruit sets and fresh and dry mass.

Five plants were taken from each lot and their averages were calculated. The leaves selected for these tests from the last two observations were also used for chemical analysis. Leaves of dark green colour were marked 5 on scale of 1 to 5 . Yellow coloured leaves were marked 1 on the scale.

The analyses of the irrigation water. resource water and of the leaves were carried out at the Arava field service laboratory.

Harvesting began on April 11 and ended on June 15. Altogether thirteen harvests were made. All the fruits were counted, weighed and sorted according to their suitability for export. From harvests number five and eight (on May 2 and 12, respectively) ten fruits were taken from each plot for shelf-life tests. They were of equal sizes as far as possible and at a stage when cracking started around the stem, were round and free of pests and fully netted.

The tests were carried out in a growing chamber where constant temperature of 18 to $22^{\circ} \mathrm{C}$ was maintained, the number of days until the fruit collapsed was taken as an indicator. Twenty fruits from each plot, of harvests 3 and 6 (dated April 24 and May 6, respectively) at uniform stage of ripening (cracking around the stem), of similar size and colour, fully netted and free from diseases, were examined using a manual refractometer as to the total level of soluble solids. 


\section{RESULTS}

\section{A. Plant Examination}

The phenomenon most conspicuous throughout the tests was the difference in general aspect of the plants. The leaf blades of the plants irrigated with magnetically treated water differed in colour, size and shine from those of the control plants. This difference was preserved until harvesting had been discontinued.

Leaves of the plants irrigated with treated water were darker and characteristic yellowing of adult leaves in the course of their aging was not observed but did occur in control plants. The leaves of the plants irrigated with treated water were smaller and of a characteristic brightness. Characteristic results are summarized in Table I.

Another prominent difference was the fact that the treated plants continued to grow without interruption, the date of the end of harvesting was dictated by the need of sanitization and not by comparison with control plants. These control plants behaved normally and their growth ceased almost entirely after the second setting cycle.

No difference was observed in other plant parameters, namely the length of central stem, the number of internodes, the number of female flowers and the fruit sets.

When examining the chemical composition of various sections of the plants, significant differences were found to exist in the nutrient content in treated and untreated plants (Tables II to IV).

\section{B. Composition of the irrigation water and of the soil solution}

The determination of the electrical conductivity and of the chemical composition of the irrigation water as sampled from the drippers produced no significant difference.

On the other hand, the tests of the resource water for nutrients in the soil solution did show significant differences that were maintained throughout the entire period of growth, as is shown in Table $V$ and Figures 1 to 6. 


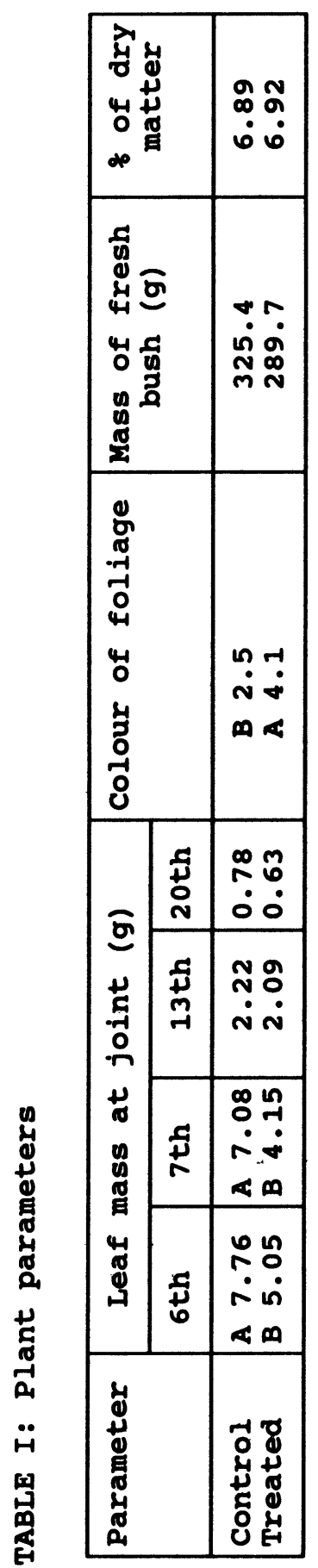

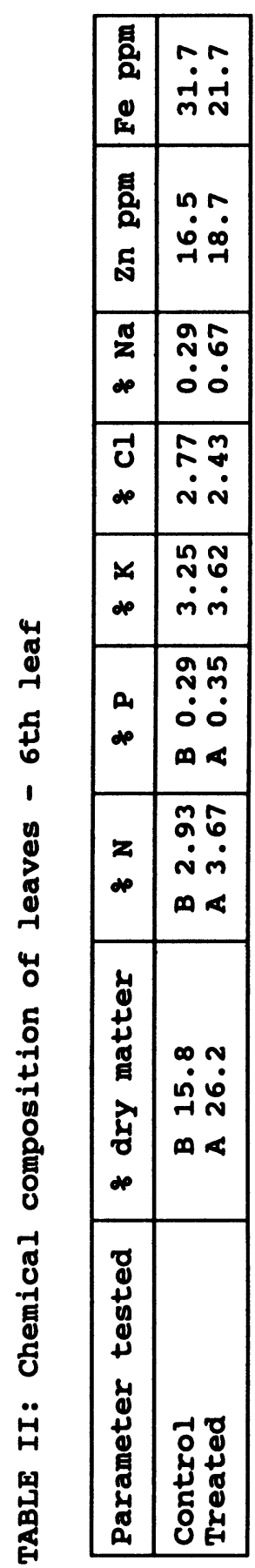



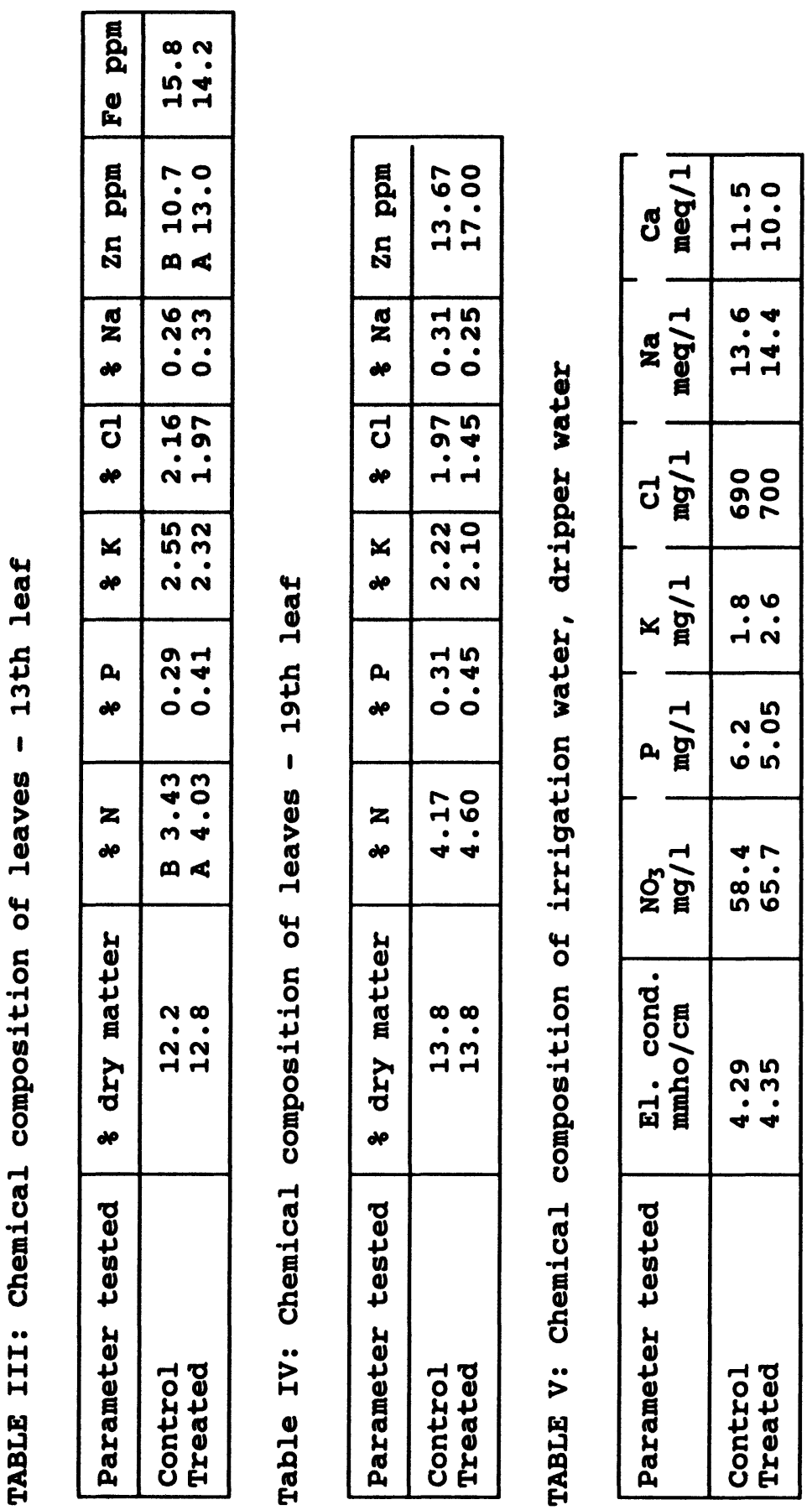


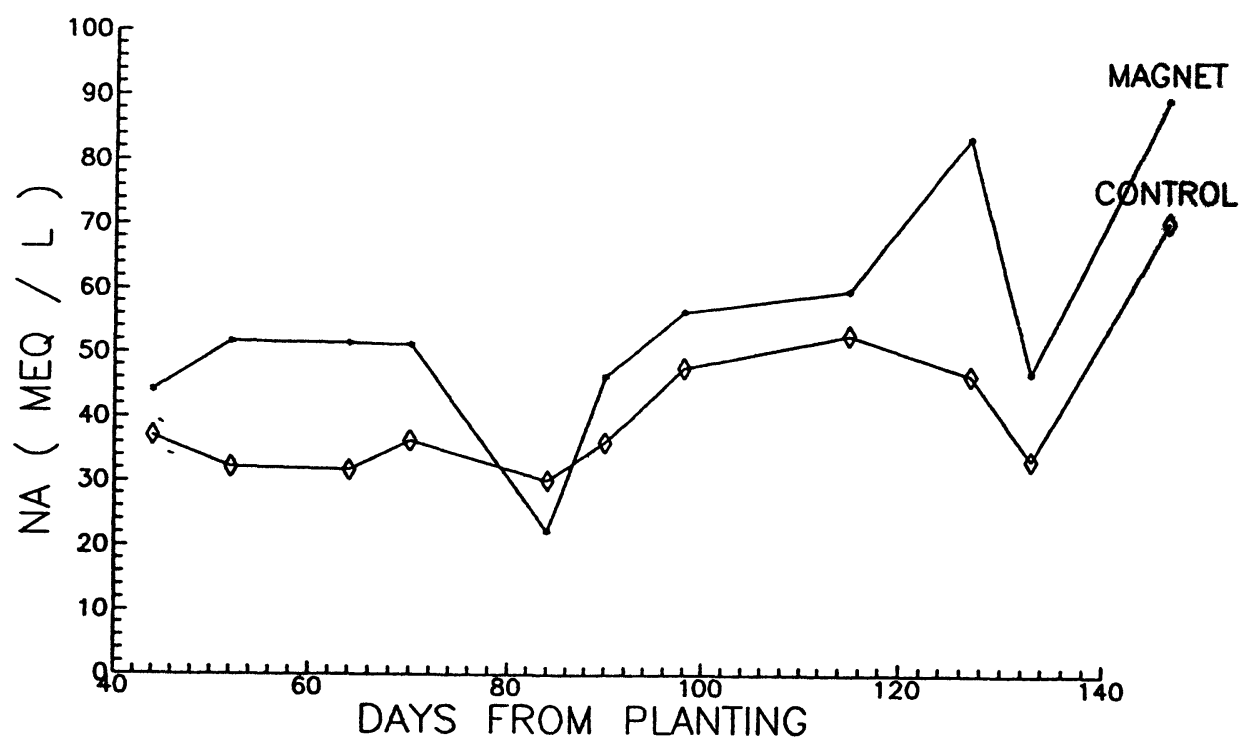

FIGURE 1. Concentration of $\mathrm{Na}$ in soil solution

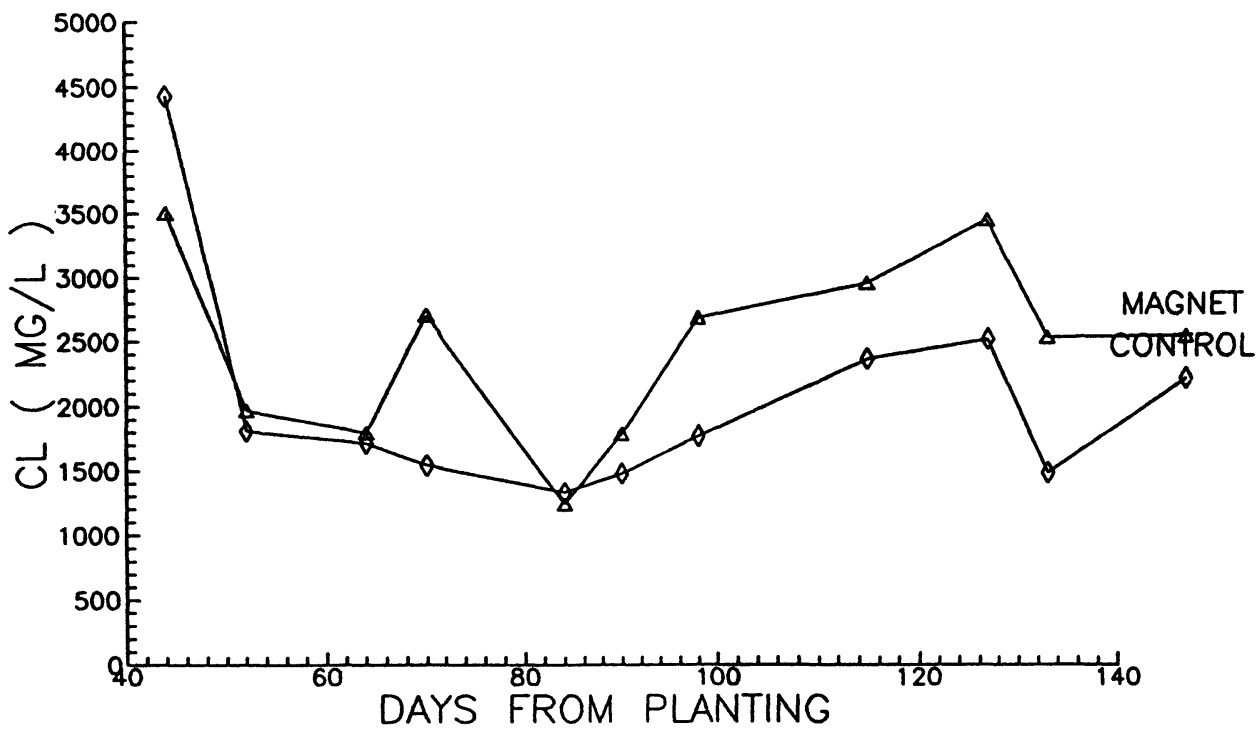

FIGURE 2. Concentration of $\mathrm{Cl}$ in soil solution 

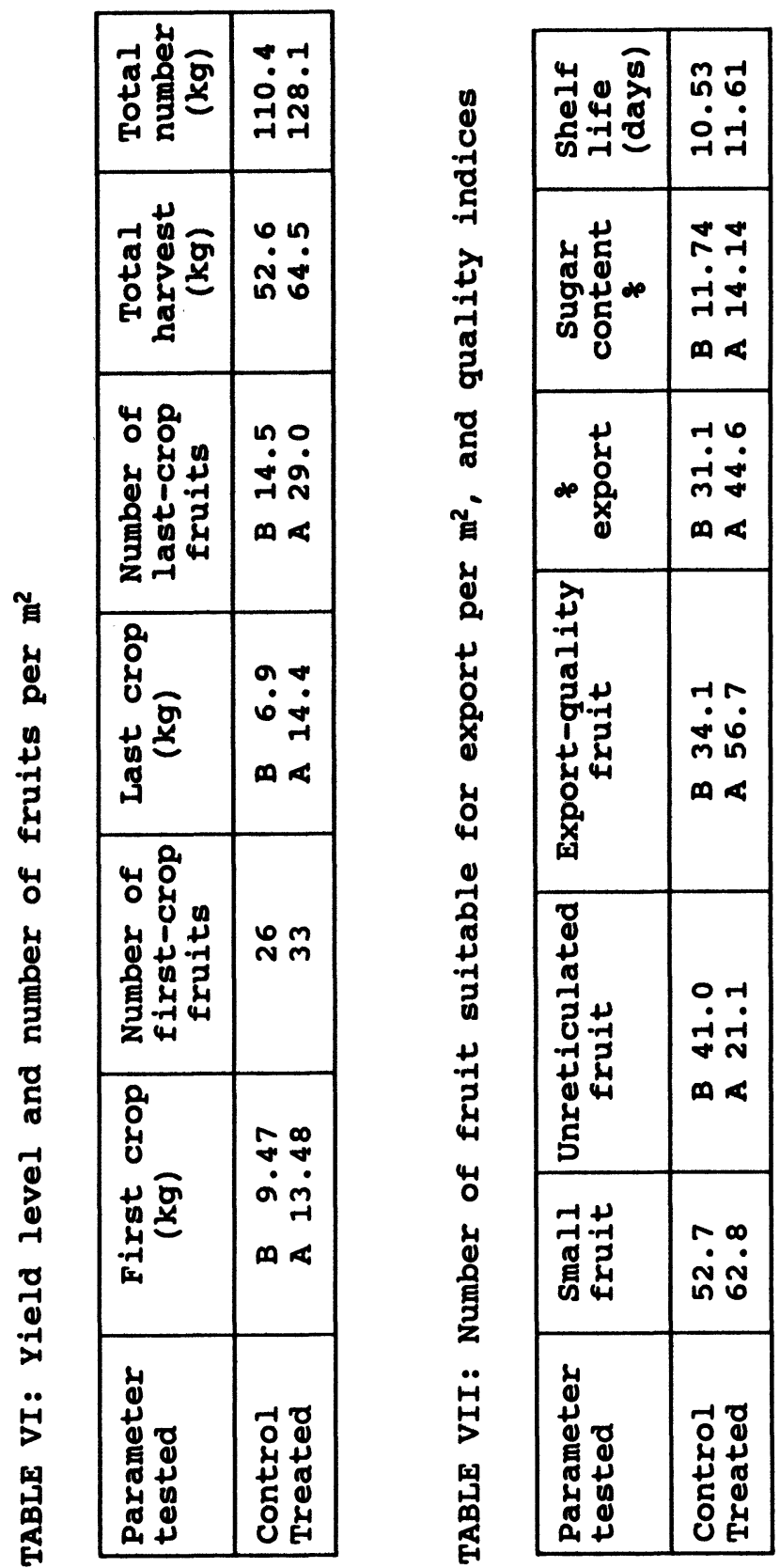


\section{Yield}

Considerable differences were observed between treated and control samples in the first and the last harvests, in the overall yield and in the number of fruits produced, as is shown in Table VI and Figure 7.

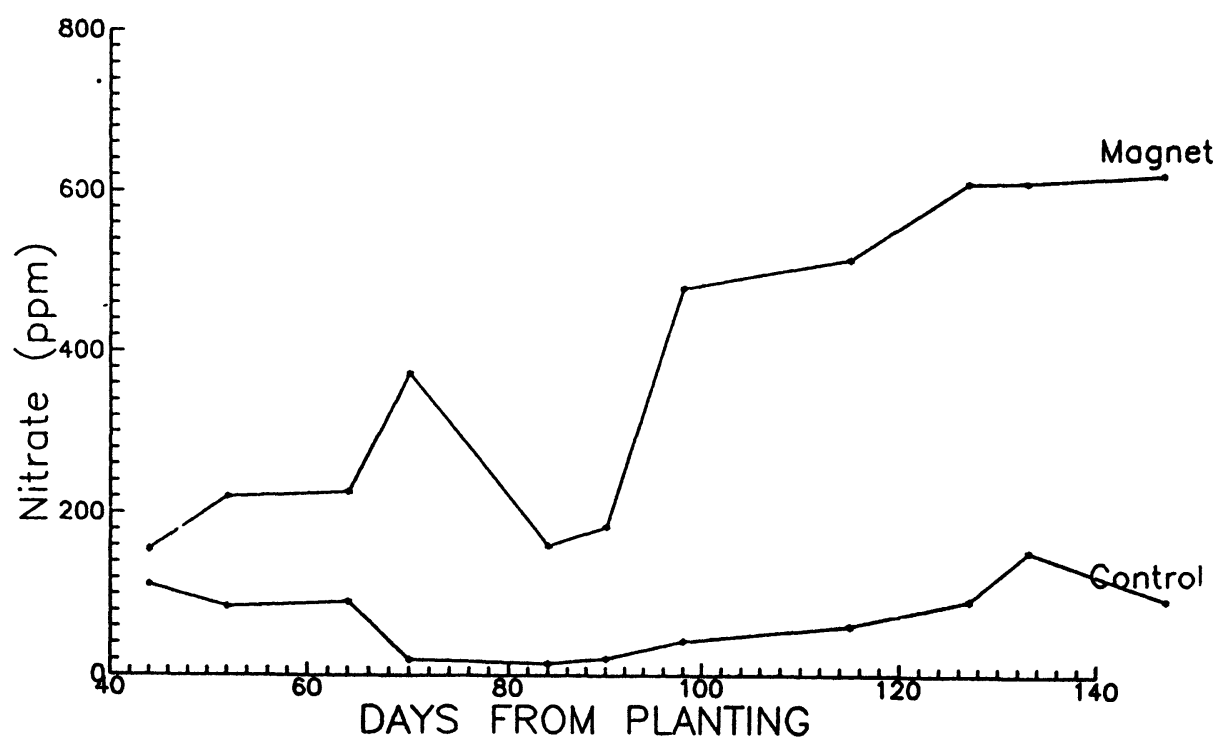

FIGURE 3. Concentration of nitrate in soil solution

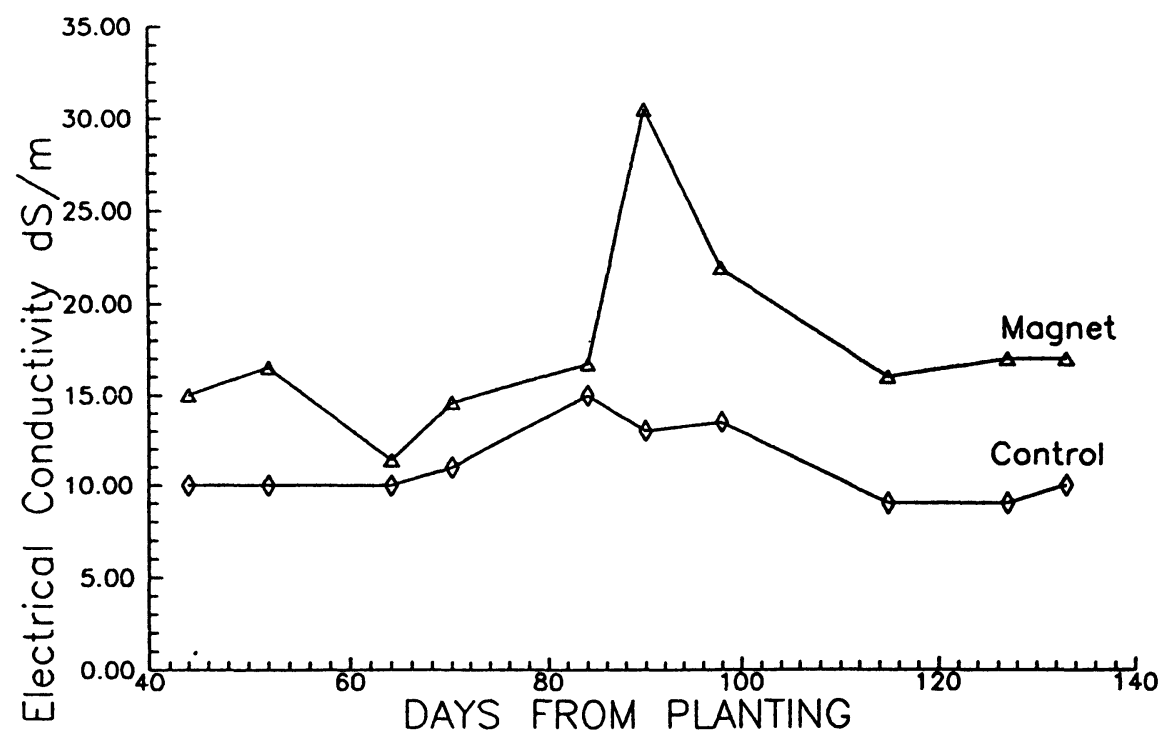

FIGURE 4. Electrical conductivity of soil solution 


\section{Quality}

Two principal reasons for rejection of fruit for export during the trials were insufficient netting and fruit size.

The average size of the fruits grown in plots irrigated with magnetically treated water was larger than that of of the control fruits (503.5 g compared to $472 \mathrm{~g}$ ). Furthermore, better netting of the fruit irrigated with magnetically treated water increased the yield for export by 53 per cent compared to the control fruits, and the number of fruits increased by 29.4 per cent.

Significant was the increase in the level of sugar, on average by 20 per cent. In individual fruits the sugar content as high as 18.4 per cent was measured which is particularly remarkable for the Arava variety which is not, as a rule, noted for high sweetness (Table VII).

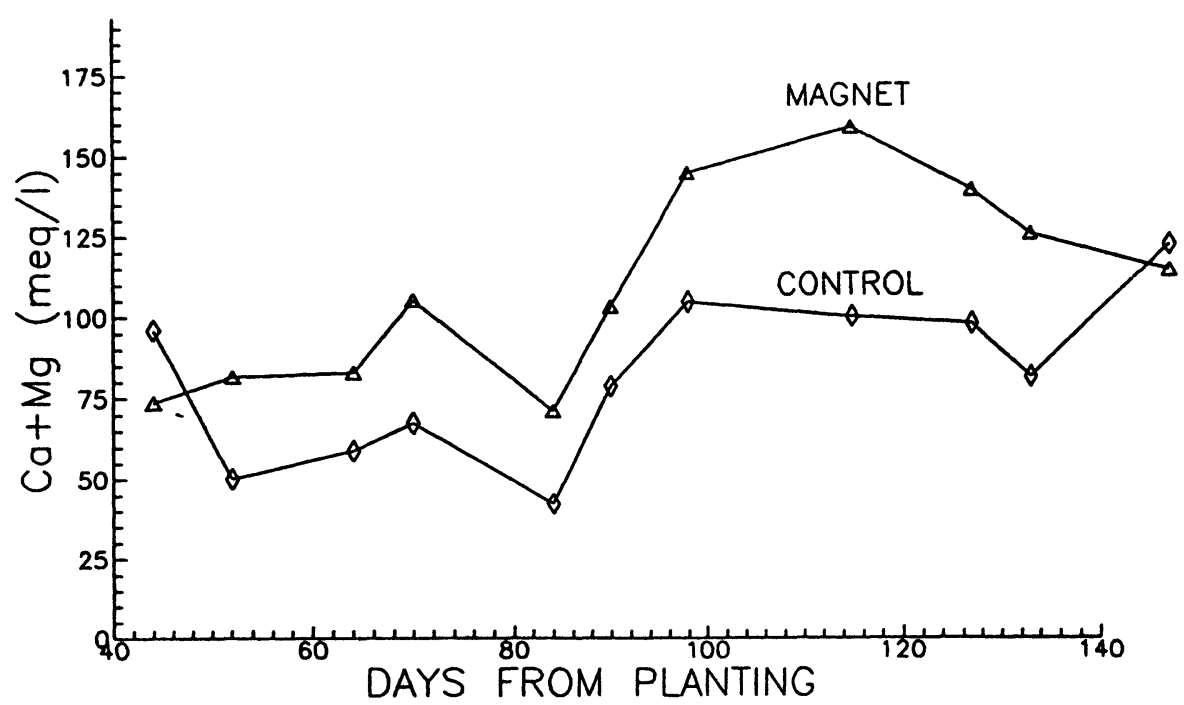

FIGURE 5. Concentration of $\mathrm{Ca}+\mathrm{Mg}$ in soil solution

\section{DISCUSSION AND CONCLUSIONS}

The irrigation of spring melons with water treated by passing it through a magnetic system affected number of parameters characterizing the plants. It was 
possible to distinguish visually the treated lots of the experimental field from the control lot.

Most phenomena observed in the trials resembled the appearance of melons irrigated with water of high salinity: dark green leaves smaller in size and shiny. The increase in the content of total soluble solids and early ripening are also known from growing the fruits in conditions of high salinity $[4,5,6,7,8]$.

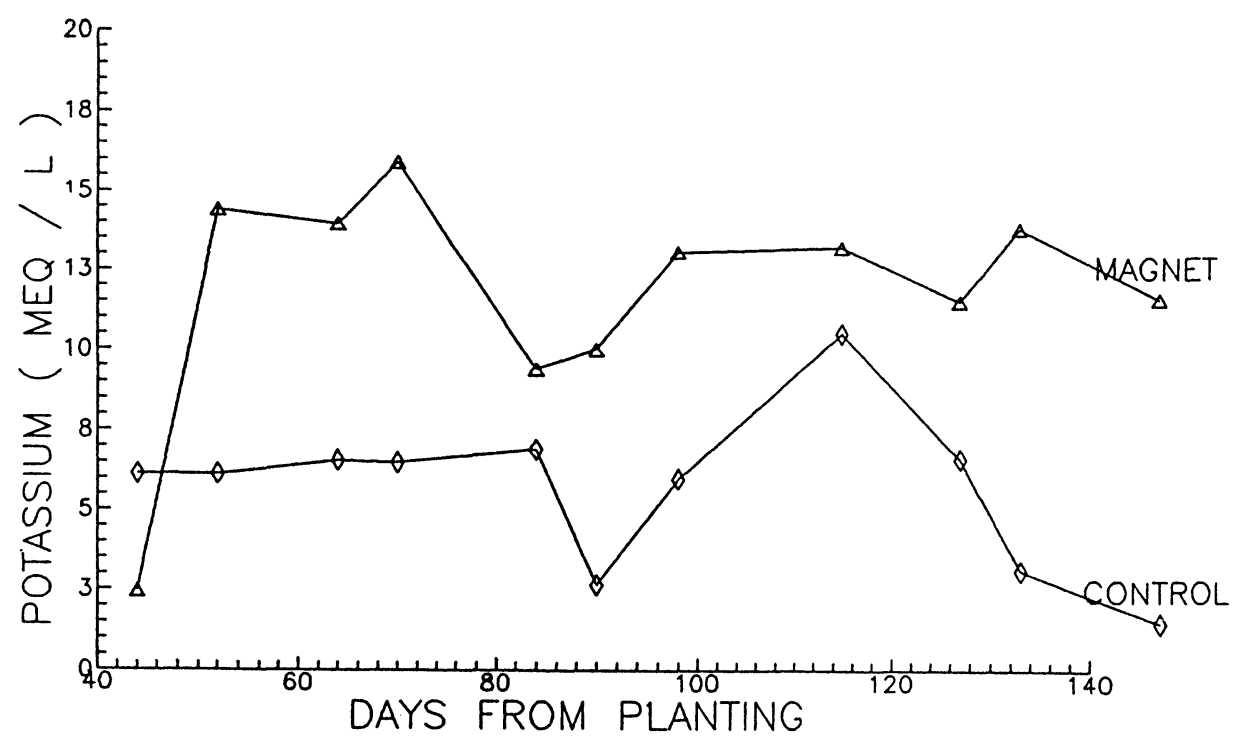

FIGURE 6. Concentration of $\mathrm{K}$ in soil solution

Since the level of electrical conductivity and of nutrients in the soil solutions were high in the treated lots, the effect observed resembled that of salt. Prominent differences between treatment with high level of salts and exposure to the magnetic field were the size of the fruit and continuing fruit bearing, while the number of fruits is, as a rule, not affected $[4,5,9]$.

Melon plants irrigated with brackish water tend to complete the growth early $[4,6$, 10]. The principal influence was in preventing the yellowing of the mature leaves. With plants irrigated with treated water the mature leaves preserved their green colour, the fact that affected such parameters of quality as size, sugar level and reticulation $[9,11]$.

All these factors contributed to a considerable increase in the percentage of fruits of export quality and in the overall yield for export. 
In the future, the research should concentrate on the investigation of the effect of magnetically treated water on plants. The mechanism of the action must be understood. Another point for future work is irrigation with solutions containing considerably lower concentrations of fertilizer, since the concentrations measured in soil solutions were appreciably higher in the lots irrigated with magnetically treated water. An attempt must be made to distinguish the effect of salination from that of magnetically treated water in order to examine the influence of the treatment on individual parameters of quality and on prevention of leaf yellowing, with all aspects that this prevention entails.

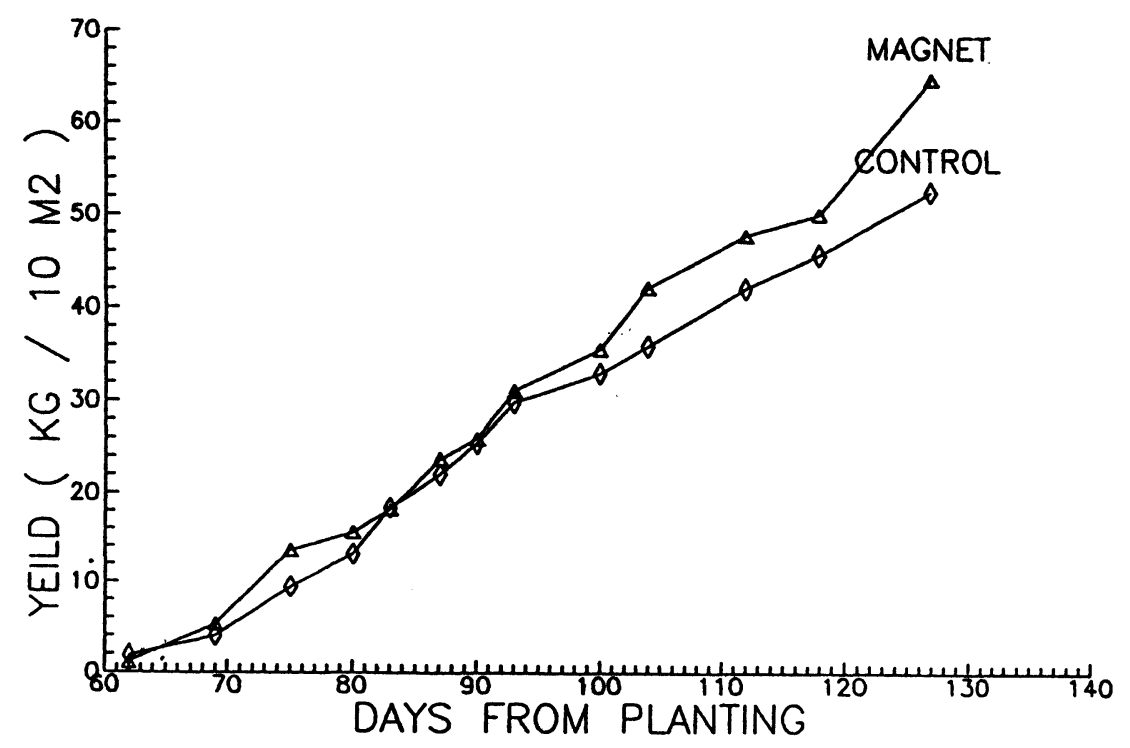

FIGURE 7. Fruit yield as a function of number of days from planting

It is recommended to examine, in the future, the magnetic treatment in an artificial medium in order to isolate the influence of the soil. An examination of influence of irrigation with magnetically treated water on other cultures is essential for the study and examination of general validity of the phenomenon.

\section{REFERENCES}

1. I. Lin and J. Yotvat, Hassadeh 68, 2419 (1988)

2. K. Syers, NZ Farmer No. 4, 24 (1983)

3. P.Pavlov, S. Gyurov and D. Parmakov: Fiziologiya na rastenijata 9, 65 (1983) 
4. M. Harari, S. Arad, I. Mizrahi and A. Shani: The influence of brackish water intended for agricultural use on elements of yield of tomato varieties. "Arava" Research Station (1982)

5. M. Harari and A. Barnea: The effect of irrigation water salinity on elements of yield and quality of sugar melons. "Arava" Research Station (1984)

6. L. Bernstein: Hassadeh 41, 109 (1961)

7. A. Meiri, Z. Plout and L. Pincas, Hassadeh 61, 511 (1981)

8. M. Nayuka, M. Masui and A. Ishida, J. Jap. Soc. Hort.Sci. 55(3), 165 (1984)

9. H. Nerson et al., Hassadeh 68,1716 (1988)

10. D. Pasternak et al., Hassadeh 58, 2114 (1978)

11. H.S. Bhella, J. Amer. Sol. Hort. Sci. 110(6), 793 (1985)

(*) Developed in Israel

I.J.Lin received the B.Sc. degree in ore dressing in 1963 and the M.Sc. and D.Sc. degrees in 1968, all from Technion- Israel Institute of Technology, Haifa.

He has been a staff member of Technion since 1966. in 1970- 71 he was a Visiting assistant Professor at the Henry Krumb School of Mines, Columbia University, New York, NY. In 1974- 75 he was a Visiting Principal Scientist at the National Institute for Metallurgy, Johannesburg, South Africa. In 1981- 82 he joined the Johannesburg Consolidated Investment Company. He is currently the Professor of Mineral Engineering at the Department of Mineral Engineering, Technion. He is the author or co-author of over 300 publications on grinding, flotation, hydrocycloning, micelle systems, magnetic and dielectrophoretic separation and mineral dressing methods.

Dr. Lin is a member of the American Institute of Mining, Metallurgical and Petroleum engineers and the Institute of Mining and Metallurgy.

M. Harari: autobiography not available

Keywords: magnetic water treatment, muskmelon, fruit yield, fruit quality, electrical conductivity, soil composition. 